\title{
Global Framework for Noncommunicable Diseases: How Can We Monitor Palliative Care?
}

\author{
Liliana De Lima, MHA, Roberto Wenk, MD, ${ }^{2}$ Eric Krakauer, MD, ${ }^{3}$ Frank Ferris, MD, ${ }^{4}$ \\ Michael Bennett, MD, ${ }^{5}$ Scott Murray, MD, ${ }^{6}$ Eduardo Bruera, MD, ${ }^{7}$ and Lukas Radbruch, $\mathrm{MD}^{8}$
}

\section{Dear Editor:}

Noncommunicable diseases (NCDs) are the leading global cause of death worldwide. Of the 57 million deaths that occurred in 2008, 36 million were due to NCDs, mainly cardiovascular diseases, cancers, diabetes, and chronic lung diseases. ${ }^{1}$ The World Health Organization (WHO) Action Plan for the Global Strategy for the Prevention and Control of Noncommunicable Diseases ${ }^{2}$ addresses key components of surveillance, prevention, and care. The proposed monitoring framework includes indicators of outcomes, exposures, and health systems capacity and response.

For several years the palliative care community has advocated for systematic monitoring of palliative care at national and global levels. Although several palliative care organizations report on the status of palliative care development, ${ }^{3,4} \mathrm{WHO}$ member states have no obligation to monitor or report on palliative care, and available reports have had limited impact on the provision of care. The $\mathrm{WHO}$ revised discussion paper on the global monitoring framework ${ }^{5}$ includes a palliative care indicator, a step forward that is welcomed by the international palliative care community. The proposed indicator is:

Access to palliative care assessed by morphine-equivalent consumption of strong opioid analgesics (excluding methadone) per death from cancer.

The inclusion of a palliative care indicator is a crucial step forward in that it acknowledges that pain relief and palliative care as among the top 12 issues on the global health agenda. However, the proposed indicator has several major limitations and weaknesses. This letter reviews these limitations and describes a proposal submitted to WHO to strengthen the indicator and eliminate some of these weaknesses.

1. The quality and scope of the cancer registries in developing countries are inadequate. As stated in the revised WHO discussion paper: "...there remains a notable lack of high-quality population based cancer registries in
Africa, Asia and Latin America, with approximately 1, 4 and 6 per cent of the populations of these respective regions being monitored." (12) Another WHO publication indicates there are more than 200 population-based cancer registries covering only about $5 \%$ of the world's population, and the proportion is much greater in developed countries than in developing ones. ${ }^{6}$ Moreover, in developing countries, registries are likely to cover primarily urban areas. It is quite likely that cancer registry data in these regions systematically underestimate both incidence and mortality.

2. Using cancer mortality would distort the real need for opioids. In addition to treatment of cancer pain, strong opioids are also essential for the treatment of pain from other causes and of other symptoms such as dyspnea as well as for the treatment of drug dependence syndrome (substitution therapy).

3. Even if this indicator would be appropriate, there are statistical weaknesses of such a combination: cancer population data (the denominator) are reported in periods of 5 or 10 years, whereas drug consumption (the nominator) is reported annually. An indicator based on the combination of such factors would result in inaccuracies and misinformation about the real status of palliative care.

4. The indicator wrongly suggests that palliative care is suitable only for cancer patients. However, patients with other major NCDs, such as advanced cardiovascular, renal, liver, lung, and neurologic disease, and patients with advanced acquired immune deficiency syndrome (AIDS), also require palliative care.

5. The indicator wrongly suggests that palliative care is equivalent to pain control and does not take into consideration other intrinsic components of palliative care, such as treatment of physical symptoms other than pain and psychosocial and spiritual support. Thus it would generate rough figures about pain treatment and less precise figures about palliative care.

\footnotetext{
${ }^{1}$ International Association for Hospice and Palliative Care, Houston, Texas.

${ }^{2}$ Programa Argentino de Medicina Paliativa Fundacion FEMEBA, Buenos Aires, Argentina.

${ }^{3}$ International Programs, Harvard Medical School Center for Palliative Care, Boston, Massachusetts.

${ }^{4}$ International Programs, The Institute for Palliative Medicine at San Diego Hospice, San Diego, California.

${ }^{5}$ Leeds Institute of Health Sciences, School of Medicine University of Leeds, Leeds, United Kingdom.

${ }^{6}$ Division of Community Health Sciences, University of Edinburgh, Edinburgh, United Kingdom.

${ }^{7}$ Department of Palliative Care and Rehabilitation Medicine, The University of Texas M. D. Anderson Cancer Center, Houston, Texas.

${ }^{8}$ Department of Palliative Medicine, University Hospital Bonn, Palliative Care Centre, Malteser Hospital Bonn/Rhein-Sieg, Bonn, Germany.
} 
6. Opioid consumption is a weak indicator of access to palliative care. Data may indicate that, in developed countries, only about $0.4 \%$ of strong opioids are consumed in palliative care, whereas in fact most of them are used for acute and chronic noncancer pain. ${ }^{7}$ The indicator may also suggest the false idea that an increase in opioid consumption is equal to (or sufficient for) the provision of good palliative care.

Based on the limitations stated above, the International Association for Hospice and Palliative Care (IAHPC) and several palliative care organizations proposed to $\mathrm{WHO}$ a modification to improve the indicator to monitor the development and progress of palliative care:

Access to palliative care assessed by per capita morphine-equivalent consumption of strong opioid analgesics (excluding methadone).

This change to the proposed indicator (morphine equivalent opioid consumption per capita) has several advantages:

1. It would avoid limitations 1 through 4 mentioned in the sections above.

2. The total population-based denominator would provide more accurate information as to the adequacy of opioid availability for all patients in need.
3. The vast majority of the countries in the world have systems in place and already report consumption of opioids on an annual basis to the International Narcotics Control Board (INCB) as part of their obligations under the Single Convention on Narcotic Drugs. This indicator would not generate any additional burden on member states.

Limitations 5 and 6 would persist and this indicator would provide only a rough estimate of the availability of opioids for pain relief.

To establish how the two indicators would differ in country monitoring, an analysis was carried out by IAHPC using consumption, population, and mortality data from 30 selected countries of the world with information provided by the WHO Department of Essential Medicines and Health Products and expert advice from Willem Scholten, PharmD. MPA, using consumption, population, and mortality data from 30 selected countries of the world. These countries were selected from all the geographical regions and the socioeconomic levels of development.

Data were obtained from available resources (Table 1):

- Total morphine equivalent consumption for fentanyl, hydromorphone, morphine, oxycodone, and pethidine was obtained. ${ }^{8}$

- Population data were identified. ${ }^{9}$

Table 1. Opioid Consumption and Mortality Data

\begin{tabular}{|c|c|c|c|c|c|c|}
\hline Country & $\begin{array}{l}\text { Total Meq } \\
\text { consumption } \\
2010(m g)^{\mathrm{a}}\end{array}$ & $\begin{array}{c}\text { Population } \\
2010\end{array}$ & $\begin{array}{c}\text { Consumption Meq } \\
\text { mg/ per capita } \\
\text { per year (2010) }\end{array}$ & $\begin{array}{c}\text { Cancer } \\
\text { mortality } \\
\text { (Globocan 2008) }\end{array}$ & $\begin{array}{c}\text { Consumption } \\
\text { Meq mg/cancer } \\
\text { death per year (2010) }\end{array}$ & $\begin{array}{c}\text { Cancer mortality } \\
\text { per } 1000 \\
\text { inhabitants }\end{array}$ \\
\hline Argentina & $602,235,000$ & $40,500,000$ & 14.87 & 60,500 & 9954.3 & 1.49 \\
\hline Australia & $4,664,240,000$ & $22,400,000$ & 208.225 & 40,889 & $114,070.8$ & 1.83 \\
\hline Brasil & $2,538,222,300$ & $193,300,000$ & 13.131 & 102,233 & $24,827.8$ & 0.53 \\
\hline Canada & $22,413,009,300$ & $34,100,000$ & 657.273 & 38,242 & $586,083.6$ & 1.12 \\
\hline Colombia & $308,581,000$ & $45,500,000$ & 6.782 & 16,674 & $18,506.7$ & 0.37 \\
\hline China & $3,826,966,000$ & $1,338,100,000$ & 2.86 & $1,222,199$ & 3131.2 & 0.91 \\
\hline Estonia & $23,912,200$ & $1,300,000$ & 18.394 & 3535 & 6764.4 & 2.72 \\
\hline Georgia & $10,106,200$ & $4,600,000$ & 2.197 & 5806 & 1740.6 & 1.26 \\
\hline Germany & $31,822,531,200$ & $81,600,000$ & 389.982 & 212,189 & $149,972.6$ & 2.60 \\
\hline Guatemala & $29,001,600$ & $14,400,000$ & 2.014 & 9120 & 3180.0 & 0.63 \\
\hline Hungary & $763,060,000$ & $10,000,000$ & 76.306 & 31,947 & $23,885.2$ & 3.19 \\
\hline Japan & $3,748,184,440$ & $127,400,000$ & 29.4206 & 342,214 & $10,952.8$ & 2.69 \\
\hline Jordan & $56,576,000$ & $6,500,000$ & 8.704 & 3445 & $16,422.6$ & 0.53 \\
\hline India & $362,584,000$ & $1,188,800,000$ & 0.305 & 633,455 & 572.4 & 0.53 \\
\hline Kenya & $67,240,000$ & $40,000,000$ & 1.681 & 22,115 & 3040.5 & 0.55 \\
\hline Malaysia & $181,260,800$ & $28,900,000$ & 6.272 & 20,130 & 9004.5 & 0.70 \\
\hline Malawi & $33,171,600$ & $15,400,000$ & 2.154 & 11,522 & 2879.0 & 0.75 \\
\hline Mexico & $715,250,200$ & $110,600,000$ & 6.467 & 77,708 & 9204.3 & 0.70 \\
\hline Peru & $65,431,000$ & $29,500,000$ & 2.218 & 24,828 & 2635.4 & 0.84 \\
\hline Romania & $201,304,500$ & $21,500,000$ & 9.363 & 46,301 & 4347.7 & 2.15 \\
\hline Serbia & $292,408,800$ & $7,300,000$ & 40.056 & 24,345 & $12,011.0$ & 3.33 \\
\hline Singapore & $58,486,800$ & $5,100,000$ & 11.468 & 6106 & 9578.6 & 1.20 \\
\hline South Africa & $2,181,178,900$ & $49,900,000$ & 43.711 & 51,436 & $42,405.7$ & 1.03 \\
\hline Ukraine & $66,555,000$ & $45,900,000$ & 1.45 & 86,621 & 768.3 & 1.89 \\
\hline Uganda & $25,485,200$ & $33,800,000$ & 0.754 & 21,317 & 1195.5 & 0.63 \\
\hline United Kingdom & $9,304,809,000$ & $62,200,000$ & 149.595 & 156,354 & $59,511.2$ & 2.51 \\
\hline United States & $1.49223 \mathrm{E}+11$ & $309,600,000$ & 481.986 & 565,644 & $263,810.6$ & 1.83 \\
\hline Vietnam & $120,370,600$ & $88,900,000$ & 1.354 & 82,006 & 1467.8 & 0.92 \\
\hline
\end{tabular}

a The morphine equivalence ratios for the different opioids and their DDDs are those used by the WHO Collaborating Centre in for Drug Statistics Methodology in Oslo, Norway (see reference 10). The ratios used in this analysis may vary from others and their differences are not the focus of this letter.

Meq, morphine equivalence. 
- Total consumption per capita of each medication was converted to "morphine equivalents" using their relative effectiveness as expressed by WHO's Defined Daily Dose (DDD). ${ }^{10}$ (The DDD is a unit of measurement used for comparative and statistical purposes and does not necessarily reflect the Prescribed Daily Dose or the best treatment approach. The adequate therapeutic dose is a medical decision determined by each case.)

- Using the cancer mortality data from the IARC/WHO Globocan Database 2008, the opioid consumption per cancer death was calculated. ${ }^{11}$

The morphine equivalent consumption per capita indicates that Canada, the United States, Germany, Australia, and the United Kingdom reported above $140 \mathrm{mg}$ per capita in 2010. This is consistent with consumption trends from previous years. Of the selected countries, 12 countries (China, Peru, Georgia, Malawi, Guatemala, Kenya, Ukraine, Vietnam, Uganda, India, Romania, and Malawi) reported consumption of less than $2 \mathrm{mg}$ per capita.

In comparison, morphine equivalent consumption per cancer deaths would result in extremely large numbers. For example, every cancer patient who died in Canada would seem to have consumed more than $586,000 \mathrm{mg}$, almost 900 times the consumption per capita. In the same way, the indicator would imply that each cancer patient who died in Colombia consumed the equivalent of more than 18,000 mgs per year, almost 3,000 times the consumption per capita.

TAble 2. Comparison between the Two Indicators

\begin{tabular}{|c|c|c|c|}
\hline Country & $\begin{array}{l}\text { Meq mg/per } \\
\text { capita per } \\
\text { year (2010) }\end{array}$ & $\begin{array}{c}\text { Meq mg/ } \\
\text { cancer death } \\
\text { per year (2010) }\end{array}$ & $\begin{array}{c}\text { Ratio cons/ } \\
\text { cancer deaths } \\
\text { cons/per } \\
\text { capita (2010) }\end{array}$ \\
\hline Colombia & 6.78 & $18,506.72$ & 2728.80 \\
\hline Brazil & 13.13 & $24,827.82$ & 1890.78 \\
\hline Jordan & 8.70 & $16,422.64$ & 1886.79 \\
\hline India & 0.31 & 572.39 & 1876.69 \\
\hline Kenya & 1.68 & 3040.47 & 1808.73 \\
\hline Uganda & 0.75 & 1195.53 & 1585.59 \\
\hline Guatemala & 2.01 & 3180.00 & 1578.95 \\
\hline Malaysia & 6.27 & 9004.51 & 1435.67 \\
\hline Mexico & 6.47 & 9204.33 & 1423.28 \\
\hline Malawi & 2.15 & 2878.98 & 1336.57 \\
\hline Peru & 2.22 & 2635.37 & 1188.17 \\
\hline China & 2.86 & 3131.21 & 1094.83 \\
\hline Vietnam & 1.35 & 1467.83 & 1084.07 \\
\hline South Africa & 43.71 & $42,405.69$ & 970.14 \\
\hline Canada & 657.27 & $586,083.61$ & 891.69 \\
\hline Singapore & 11.47 & 9578.58 & 835.24 \\
\hline Georgia & 2.20 & 1740.65 & 792.28 \\
\hline Argentina & 14.87 & 9954.30 & 669.42 \\
\hline Australia & 208.23 & $114,070.78$ & 547.82 \\
\hline United States & 481.99 & $263,810.57$ & 547.34 \\
\hline Ukraine & 1.45 & 768.35 & 529.89 \\
\hline Romania & 9.36 & 4347.74 & 464.35 \\
\hline United Kingdom & 149.60 & $59,511.17$ & 397.82 \\
\hline Germany & 389.98 & $149,972.58$ & 384.56 \\
\hline Japan & 29.42 & $10,952.75$ & 372.28 \\
\hline Estonia & 18.39 & 6764.41 & 367.75 \\
\hline Hungary & 76.31 & $23,885.18$ & 313.02 \\
\hline Serbia & 40.06 & $12,011.04$ & 299.86 \\
\hline
\end{tabular}

cons, consumption; Meq, morphine equivalence.
Similar distortion would occur in data for all the countries included in the study (Table 2).

More important, countries with lower socioeconomic levels of development are at a further disadvantage, as they have a higher ratio, placing them in the top half of Table 2 . This means that the consumption per cancer death indicator for Jordan is higher than that for Serbia or even for Japan, even though the consumption per capita is only one-fourth and one-third, respectively.

A denominator based on cancer mortality numbers would be extremely and often erroneously small. Thus the resulting indicator would overestimate the adequacy of opioid availability and negatively impact efforts to make strong opioids accessible to all patients who need them.

The distortion between the consumption per capita and the consumption per cancer death would occur not only in the 30 countries included in this study but in all countries; with the distortion being proportional to the status of cancer registries (the less the population is monitored for cancer, the greater the distortion). This would also mean that cross-country comparisons would be of little value, especially between those that have comprehensive cancer registries in place and developing countries, where $5 \%$ or less of the population is monitored.

The consumption per cancer death indicator would further distort the situation in countries with low socioeconomic status. In many of these countries palliative care has been initiated in response to the challenge of human immunodeficiency virus (HIV)/AIDS, in close collaboration with antiretroviral treatment, and palliative care services are targeted toward this patient group. Patients with NCDs often find it difficult to access palliative care in these countries, and most often do not receive the opioid treatment they need. Thus the higher consumption per cancer death indicator would directly counteract the purpose of the Global Framework, as it would show higher values in countries where fewer patients with NCDs receive adequate opioid treatment.

Opioid treatment is required for other indications than cancer pain, including acute pain, pain in HIV/AIDS, postsurgical pain, pain in women during labor, dyspnea, and substitution therapy. Large consumption numbers with the consumption per cancer death indicator will also negatively impact the efforts to improve availability of opioids for these other indications.

The palliative care community recognizes the importance of cancer registries and advocates for and supports appropriate disease monitoring and reporting systems. However, developing a palliative care indicator based on unreliable data will lead to a weak indicator. Using opioid consumption per capita will provide a much stronger indicator with more relevance to the goals of the Global Framework.

The palliative care community is also aware that currently there are many limitations to monitoring palliative care and it will continue to work with member states and civil society to support the development of palliative care globally, so that a comprehensive, more accurate palliative care indicator can be developed, such as:

1. Palliative care capacity (number of services and fulltime palliative care providers) per 100,000 inhabitants.

2. Proportion of national disease strategies that include palliative care components or programs. 
3. Proportion of university programs for health professions that include palliative care curricula in undergraduate and programs in postgraduate levels, including academic chairs and specialty training.

\section{References}

1. Alwan A et al.: Monitoring and surveillance of chronic noncommunicable diseases: Progress and capacity in highburden countries. Lancet 2010;376:1861-1868.

2. WHO: WHO Action Plan for the Global Strategy for the Prevention and Control of Noncommunicable Diseases. Geneva: World Health Organization, 2008.

3. Lynch $\mathrm{T}$ et al.: Mapping levels of palliative care development: A global update 2011. London: Worldwide Palliative Care Alliance. www.thewpca.org/resources / (Last accessed October 12, 2012).

4. Centeno C, Clark D, Lynch T et al.: Facts and indicators on palliative care development in 52 countries of the WHO European region: Results of an EAPC task force. Palliat Med 2007;21:463.

5. WHO: A comprehensive global monitoring framework, including indicators, and a set of voluntary global targets for the prevention and control of non-communicable diseases. July 25, 2012, p. 10. http://www.google.com/url?sa =t\&rct= $\mathrm{j} \& \mathrm{q}=\&$ \&esc $=\mathrm{s} \&$ source $=$ web\&cd $=$ rja\&ved $=0 \mathrm{CDYQFjAB \&}$ url $=$ http $\% 3 \mathrm{~A} \% 2 \mathrm{~F} \% 2 \mathrm{Fwww}$.searo.who.int $\% 2$ Flinkfiles $\% 2$ fhnd_ gmf.pdf\&ei = XxGUL7fo4rFyAHjloHYDQ\&usg = AFQjCNG-8n 0ftwr6N-1CyvxVAk295nmG8Q (Last accessed October 2, 2012).

6. WHO - IARC. The role of cancer registries. In: Dos Santos Sliva I: Cancer Epidemiology: Principles and Methods. Lyon:
IARC, 1999, pp. 385-404). www.iarc.fr/en/publications/ pdfs-online/epi/cancerepi/CancerEpi-17.pdf (Last accessed October 2, 2012).

7. Seya MJ, Gelders SFAM, Achara UA, Milani B, Scholten WK: A first comparison between the consumption of and the need for opioid analgesics at country, regional and global level. J Pain Palliat Care Pharm 2011;25:6-18.

8. INCB: Narcotic Drugs Technical Reports. Report 2011 Estimated World Requirements for 2012 - Statistics for 2010. www.incb.org/incb/en/annual-report-2011.html (Last accessed September 9, 2012).

9. Population Reference Bureau: World Population Data Sheet 2010. www.prb.org/pdf10/10wpds_eng.pdf (Last accessed September 8, 2012).

10. WHO Collaborating Centre for Drug Statistics Methodology. www.whocc.no/atc_ddd_index $/$ ?code $=$ N02AA\&show description = no (Last accessed September 12, 2012).

11. International Agency for Research in Cancer/ WHO: Globocan 2008 Cancer Incidence, Mortality and Prevalence Worldwide. http://globocan.iarc.fr/ (Last accessed ember 9, 2012).

Address correspondence to: Liliana De Lima, MHA

IAHPC

5535 Memorial Drive

Suite F - PMB 509

Houston, TX 77007

E-mail: ldelima@iahpc.com 